\title{
ESTUDO DA SUBSTITUIÇÃO PARCIAL DO PÓ DE PEDRA POR PÓ DE BALÃO EM BLOCOS PRÉ- MOLDADOS DE CONCRETO*
}

\author{
Amanda Martins FernaQdes ${ }^{1}$ \\ Jaqueline de Assis Oliveira ${ }^{2}$ \\ Leonardo Lúcio de Araújo Gouveia ${ }^{3}$ \\ Carlos Augusto Souza de Oliveira ${ }^{4}$ \\ Ricardo Luiz Perez Teixeira ${ }^{5}$
}

\section{Resumo}

O presente trabalho tem como objetivo estudar a influência da adição do rejeito de pó de balão nas propriedades mecânicas do concreto destinado à fabricação de pavers, visto que a indústria da construção civil é a maior responsável pela geração de resíduos, sendo responsável pelo consumo de aproximadamente $40 \%$ dos recursos naturais extraídos. Sendo assim, o rejeito foi analisado granulometricamente por peneiramento e foram feitos dois traços, um denominado traço referência e o outro denominado traço substituído, sendo este último com adição de $4 \%$ em massa do pó de balão. A partir dos traços calculados foram moldados corpos de prova e avaliados a resistência à compressão destes. Os corpos de prova moldados a partir do traço substituído exibiram maior resistência à compressão tanto na idade de 7 dias quanto na idade de 28 dias, quando comparados aos corpos moldados a partir do traço referência. Esse incremento na resistência mecânica é justificado pela distribuição granulométrica do pó de balão, que por ser constituído em sua maior parte por finos inferiores a $0,15 \mathrm{~mm}$ atua preenchendo vazios, reduzindo zonas de transição interfacial e formando uma microestrutura mais refinada.

Palavras-chave: Pó de balão; Pavers; Resistência à compressão; Construção civil.

\section{STUDY OF THE PARTIAL REPLACEMENT OF STONE DUST BY BALLON POWDER IN PRECAST CONCRETE BLOCKS}

\section{Abstract}

The presente work aims to study the influence of the addition of balloon powder waste on the mechanical properties of concrete used to manufacture pavers, since the construction industry is the main responsible for the generation of waste, being responsible for the consumption of approximately $40 \%$ of all mined natural resources. Therefore, the waste was granulometrically analysed by sieving and two diferente concrete dosages were made. The first one was called reference dosage and the second one was named substituted dosage, being the latter with addition of $4 \%$ in mass of balloon powder. Using the concrete dosages calculated, concrete samples were made and their compressive strenght was evaluated. The concrete samples made from the substituted dosage showed higher compressive strenght in the age of 7 days as well as in the age of 28 days, when compared to the reference dosage. This higher compressive strenght is justified by the particle size distribution of the balloon powder, which consist mostly of thin particles below $0.15 \mathrm{~mm}$, that act filling empty spaces, reducing interfacial transition zones and forming a more refined microstructure.

Keywords: Balloon powder; Pavers; Compressive strenght; Civil construction.

1 Graduanda em Engenharia de Materiais, Universidade Federal de Itajubá- Campus Itabira, Itabira, Minas Gerais, Brasil, martinsfernandes_amanda@hotmail.com.

2 Graduanda em Engenharia Civil, Universidade Estadual de Minas Gerais- FaEnge, João Monlevade, MG, Brasil, jaquelineassisoliveira@gmail.com.

3 Geógrafo, Ms. em geografia, docente, departamento de Engenharia Metalúrgica, Universidade Estadual de Minas Gerais- FaEnge,, João Monlevade, MG, Brasil, gouveialeo@yahoo.com.br.

4 Eng. Civil, Dr. em Engenharia Metalúrgica e de Minas pela UFMG, docente e coordenador de curso, departamento de Engenharia da Mobilidade, Universidade Federal de Itajubá- Campus Itabira, Itabira, MG, Brasil, carlosoliveira@unifei.edu.br.

5 Membro da ABM, Eng. Químico, Dr. em Engenharia Metalúrgica e de Materiais pela UFRJ, docente e coordenador de curso, departamento de Engenharia de Materiais, Universidade Federal de ItajubáCampus Itabira, Itabira, MG, Brasil, ricardo.luiz@unifei.edu.br. 


\section{INTRODUÇÃO}

Atualmente, reduzir-se a quantidade de resíduos sólidos gerados pelas indústrias é uma grande preocupação dos países em desenvolvimento como o Brasil. Sabe-se que a indústria da construção civil é responsável pelo consumo de aproximadamente $40 \%$ dos recursos naturais extraídos sendo, portanto o setor responsável pela maior parte de resíduos gerados pela sociedade [1].

A incorporação desses resíduos nas matérias-primas utilizadas pela construção civil é uma maneira viável de reduzir esse problema, sendo capaz de diminuir os custos de produção e de reaproveitar diversos resíduos, como por exemplo, os plásticos, as borrachas de pneus, o pó de balão, dentre outros.

O pó de balão é um resíduo sólido, de coloração negra, oriundo da indústria siderúrgica. Esse resíduo é constituído basicamente de finos de carvão vegetal e minério e pode ser adicionado ao concreto na produção de blocos pré-moldados de concreto, os pavers [2].

No Brasil, a utilização dos pavers em determinados segmentos é definida pela Norma Brasileira ABNT NBR 9781, que trata de peças de concreto para Pavimentação - Especificação e métodos de ensaio. De acordo com essa norma, a resistência característica à compressão mínima exigida aos 28 dias de idade para pavers destinados ao tráfego de pedestres, veículos leves e veículos comerciais de linha é de $35 \mathrm{MPa}$, enquanto que para o tráfego de veículos especiais e solicitações capazes de produzir efeitos abrasivos acentuados esse valor mínimo é de $50 \mathrm{MPa}$ aos 28 dias [3].

Do ponto de vista da sustentabilidade ambiental, os pavers são bastante interessantes, uma vez que por permitirem a infiltração da água, acabam reduzindo o volume de enxurradas e erosões, melhoram a qualidade da água, reduzem os gastos públicos com recursos de drenagem e mantém a área útil do terreno [4].

Sendo assim, o estudo desse resíduo como insumo na produção dos blocos prémoldados se mostra relevante, uma vez que reduz os custos de matérias-primas e torna a produção nas siderúrgicas menos poluente e mais eficaz.

\section{MATERIAIS E MÉTODOS}

Visando caracterizar granulometricamente as amostras de pó de balão foram realizados ensaios granulométricos por peneiramento de duas amostras do resíduo, sendo as amostras passadas por peneiras de diversas aberturas, sob agitação constante.

Para posterior estudo dos efeitos da adição do pó de balão, preparou-se inicialmente, um concreto utilizando apenas matérias primas convencionais (areia, brita, cimento, água e aditivo) sem que houvesse adição do resíduo, sendo o traço utilizado para a moldagem desse concreto denominado traço referência. Em sequência, tendo como base o traço referência calculou-se um traço denominado traço substituído. Para esse traço foram utilizadas as mesmas matérias-primas havendo, entretanto, a adição do pó de balão. Em relação ao traço referência reduziu-se a massa total da areia em $4 \%$, sendo esse total substituído pelo pó de balão.

Em seguida, a partir dos traços calculados foram moldados 8 corpos de prova, sendo utilizado em 4 deles o traço referência e nos outros 4 restantes o traço substituído. Os materiais utilizados em cada traço foram despejados em uma betoneira, sendo mantidos sob agitação por aproximadamente 10 minutos. Foram 
então, moldados em corpos de prova de dimensões $10 \mathrm{~cm} \times 20 \mathrm{~cm}$, sendo o concreto despejado em 2 camadas e golpeado por 12 vezes em cada camada. Após 24 horas da moldagem os corpos de prova foram submersos em uma solução saturada de cal para dar início ao processo de cura.

Por fim, para análise da resistência à compressão dos corpos moldados foram realizados ensaios mecânicos de resistência à compressão nos corpos com idades de 7 dias e 28 dias.

\section{RESULTADOS E DISCUSSÃO}

\subsection{Granulometria do pó de balão}

A granulometria realizada para as amostras do pó de balão permitiu que se obtivesse a massa retida de cada uma das amostras, a porcentagem retida individual e a média das porcentagens retidas $(\mathrm{Md})$, bem como a porcentagem retida acumulada das amostras. Esses valores encontram-se a seguir na Tabela 1, sendo a massa da amostra M1 igual a 385,34g e a amostra M2 igual a 385,45g.

Tabela 1. Granulometria das amostras M1 e M2 de pó de balão

\begin{tabular}{c|c|c|c|c|c|c}
\hline \multicolumn{7}{c}{ GRANULOMETRIA } \\
\hline $\begin{array}{c}\text { Peneiras } \\
\text { ABNT } \\
{[\mathbf{m m}]}\end{array}$ & \multicolumn{7}{|c|}{ Massa Retida [g] } & \multicolumn{2}{c}{ \% retida individual } & $\begin{array}{c}\text { \% retida } \\
\text { acumulada }\end{array}$ \\
\cline { 2 - 6 } & M1 & M2 & M1 & M2 & M $_{\mathbf{d}}$ & \\
\hline 25,0 & 0,00 & 0,00 & 0,0 & 0,0 & 0,0 & 0,0 \\
\hline 12,5 & 23,68 & 2,62 & 6,1 & 0,7 & 3,4 & 3 \\
\hline 9,5 & 1,90 & 0,62 & 0,5 & 0,2 & 0,3 & 4 \\
\hline 6,3 & 0,80 & 3,60 & 0,2 & 0,9 & 0,6 & 4 \\
\hline 4,8 & 0,87 & 1,37 & 0,2 & 0,3 & 0,3 & 5 \\
\hline 2,4 & 2,11 & 1,99 & 0,5 & 0,5 & 0,5 & 5 \\
\hline 1,2 & 3,58 & 3,20 & 0,9 & 0,8 & 0,9 & 6 \\
\hline 0,6 & 7,94 & 7,97 & 2,0 & 2,0 & 2,1 & 9 \\
\hline 0,3 & 31,38 & 36,86 & 8,1 & 9,6 & 8,9 & 17 \\
\hline 0,15 & 91,96 & 102,71 & 23,9 & 26,6 & 25,3 & 42 \\
\hline Fundo & 219,98 & 223,46 & 57,0 & 58,0 & 57,5 & 100 \\
\hline & & & & & & \\
\hline
\end{tabular}

A análise da granulometria do pó de balão contida na tabela acima nos mostra que o resíduo estudado é constituído em sua maior parte por finos, visto que tanto nas amostras M1 quanto M2 mais de $57 \%$ da massa do material analisado encontrou-se retido no fundo, sendo o tamanho das partículas inferior a $0,15 \mathrm{~mm}$.

Em relação à tabela 1 , nota-se ainda que o resíduo analisado possui uma distribuição granulométrica de partículas uniforme, uma vez que nenhuma das amostras apresenta partículas com diâmetros superiores a $25 \mathrm{~mm}$ e que apenas $17 \%$ da massa total analisada possui diâmetro superior à $0,3 \mathrm{~mm}$. 


\subsection{Traço referência e traço substituído}

O traço referência a ser utilizado na fabricação de pavers foi calculado tendo em vista a resistência mínima exigida de $35 \mathrm{MPa}$, conforme especificado pela norma ABNT NBR 9781.

Para o traço referência os materiais utilizados foram o cimento CP-V ARI, a brita 1 (do tipo gnaisse, proveniente de rocha granítica), água, areia grossa quartzosa proveniente de um rio local e o aditivo MC Poweflow 1180. A massa específica da brita utilizada é de $\rho=2,70 \mathrm{~g} / \mathrm{cm}^{3}$, a da areia é de $\rho=2,62 \mathrm{~g} / \mathrm{cm}^{3}$ e do aditivo de $\rho=$ $1,09 \mathrm{~g} / \mathrm{cm}^{3}$. O aditivo utilizado é fabricado pela empresa MC Bauchemie, sendo um aditivo superplastificante à base de policarboxilato.

$\mathrm{Na}$ tabela 2, a seguir, encontra-se o traço em massa utilizado para a fabricação dos corpos de prova referência, sendo que a relação água/cimento utilizada foi de a/c= 0,418 .

Tabela 2. Traço referência em massa

\begin{tabular}{c|c|c|c|c}
\hline Cimento [kg] & Areia [kg] & Brita [kg] & Água $[\mathbf{k g}]$ & Aditivo [g] \\
\hline 1 & 1,57 & 1,94 & 0,418 & 5 \\
\hline
\end{tabular}

Já o traço substituído, com redução de $4 \%$ em massa de areia e adição simultânea de pó de balão correspondente ao teor reduzido encontra-se na tabela 3, abaixo.

Tabela 3. Traço substituído em massa

\begin{tabular}{c|c|c|c|c|c}
\hline Cimento $[\mathrm{kg}]$ & Areia $[\mathrm{kg}]$ & Brita $[\mathrm{kg}]$ & Água $[\mathrm{kg}]$ & Pó de balão $[\mathrm{kg}]$ & Aditivo [g] \\
\hline 1 & 1,5072 & 1,94 & 0,418 & 0,0628 & 5 \\
\hline
\end{tabular}

\subsection{Análise da resistência à compressão}

Os ensaios mecânicos de resistência à compressão realizados nos corpos de prova nas idades de 7 e 28 dias permitiram plotar um gráfico comparando à resistência do traço referência e do traço substituído nas duas idades estudadas, conforme mostra a figura 1.

Na figura 1 a barra de número 1 representa o corpo de prova com traço referência na idade de 7 dias, enquanto as barras 3 e 4 representam os corpos de prova com traço referência na idade de 28 dias. A barra 2, por sua vez, representa o corpo de prova com traço substituído na idade de 7 dias, e a barra 5 representa esse mesmo traço na idade de 28 dias. Em todos os valores de resistência à compressão obtidos, deve-se considerar um erro de $\pm 0,5 \mathrm{MPa}$, proveniente do equipamento utilizado para a medição. 


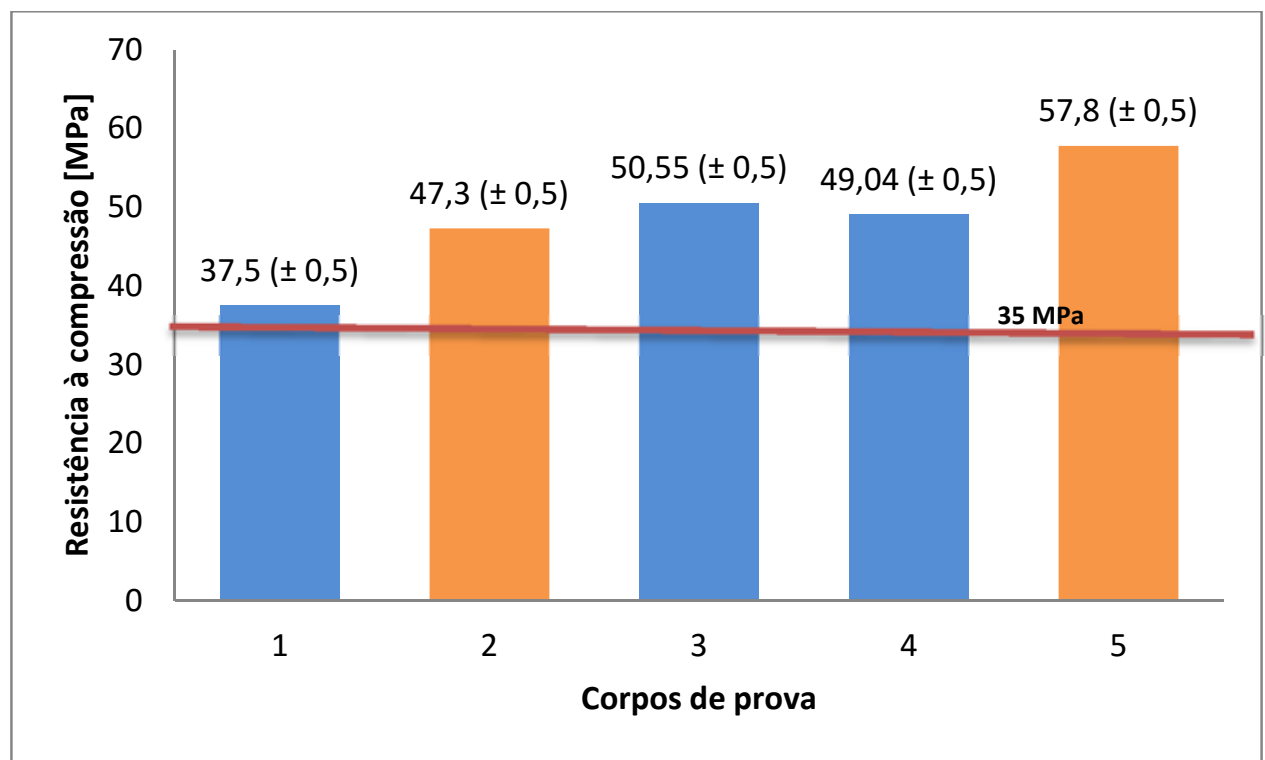

Figura 1. Gráfico da resistência à compressão nas idades estudadas x corpos de prova moldados a partir do traço referência e do traço substituído.

Analisando o gráfico acima é possível constatar que a adição de apenas $4 \%$ em massa do pó de balão com a granulometria estudada promove um aumento na resistência à compressão em ambas as idades estudadas. Na idade de 7 dias a comparação entre o corpo de prova referência e o corpo de prova substituído nos fornece um aumento de aproximadamente $26 \%$ na resistência à compressão, enquanto que aos 28 dias esse aumento é de aproximadamente 16\%, para corpos de mesma idade.

Ainda em relação ao gráfico plotado, é possível correlacionar os dados obtidos pelos testes de resistência à compressão aplicados aos corpos de prova moldados com o traço referência com a análise granulométrica do pó de balão, contida na tabela 1.

Por ser constituído em sua maior parte por finos, o pó de balão aumenta as propriedades mecânicas do concreto, uma vez que atua preenchendo vazios, incrementando a densidade da argamassa e reduzindo a porosidade na zona de transição argamassa-concreto, ao mesmo tempo em que leva à formação de uma microestrutura mais refinada [5].

Por fim, nota-se ainda que somente a adição de $4 \%$ em massa do pó de balão (com a granulometria estudada na Tabela 1) no concreto já permite que este possa ser utilizado também na fabricação de pavers para o tráfego de veículos especiais e solicitações com efeitos abrasivos acentuados, que conforme a ABNT NBR 9781 devem possuir resistência mínima à compressão de $50 \mathrm{MPa}$.

\section{CONCLUSÃO}

A análise granulométrica do pó de balão e os testes de resistência à compressão realizados nos corpos de prova moldados a partir do traço referência e do traço substituído permitem concluir que a adição de somente $4 \%$ em massa desse rejeito com a granulometria estudada já é capaz de aumentar a resistência à compressão tanto aos 7 quanto aos 28 dias de idade, fazendo com que esse concreto possa ser utilizado também em pavers destinados ao tráfego de veículos especiais e solicitações com efeitos abrasivos acentuados, que possuem exigência de resistência mínima de $50 \mathrm{MPa}$, conforme a ABNT NBR 9781. 
O aumento na resistência à compressão dos corpos de prova substituídos pode ser atribuído à distribuição granulométrica do pó de balão, que por ser constituído em sua maior parte por finos inferiores a $0,15 \mathrm{~mm}$ atua preenchendo vazios, reduzindo zonas de transição interfacial e formando uma microestrutura mais refinada.

Dessa forma, a adição do pó de balão ao concreto destinado à pavers se mostra bastante eficaz, uma vez que aumenta as propriedades mecânicas do concreto ao mesmo tempo em que reduz a quantidade desse resíduo no meio ambiente e auxilia na produção de um material de menor custo que o tradicional.

\section{Agradecimentos}

Os autores gostariam de agradecer ao CNPq pela bolsa concedida, ao grupo de pesquisa MATCIME - Campus Itabira e ao laboratório de Materiais de Construção do Departamento de Engenharia da Mobilidade da UNIFEI - Campus Itabira.

\section{REFERÊNCIAS}

1 SANTOS, J.R. Betão com agregados grossos reciclados de betão. Concreto \& Construções. 2005; 37:10-14.

2 TELLES, Fernanda Fumaneli Goes. et al. Reutilização de resíduos finos oriundos do processo siderúrgico. VIII Congresso Brasileiro de Engenharia Química em Iniciação Científica. 2009 [acesso em 8 fev. 2016]. Disponível em:< http://www.cobeqic2009.feq.ufu.br/uploads/media/108922822.pdf>.

3 ABNT - Associação Brasileira de Normas Técnicas. Peças de concreto para Pavimentação - Especificação e métodos de ensaio. NBR - 9781. Rio de Janeiro, 2013.

4 MARCHIONI, Mariana; SILVA, Cláudio Oliveira. Pavimento Intertravado Permeável Melhores Práticas. Associação Brasileira de Cimento Portland (ABCP). 2011 [acesso em 8 fev. 2016]. Disponível em:< http://ninamartinelli.com.br/downloads/cartilha_pav_intertravado_permeavel.pdf $>$.

5 SILVA, Anna Jacqueline Santos. et al. Desenvolvimento de concreto colorido com alta resistência por meio do uso de pigmentos, cura térmica e pó de quartzo. Congresso Técnico Científico da Engenharia e da Agronomia. 2015[ acesso em 8 fev. 2016]. Disponível em:< http://www.confea.org.br/media/Civil_desenvovimento_de_concreto_colorido_de_alta_r esistencia_por.pdf >. 